\title{
Ротенберг Натали
}

МУЗЫКА ПУБЛИЧНЫХ ПРОСТРАНСТВ: ЗВУЧАЩИЕ АРТ-ОБЪЕКТЫ В УРБАНИСТИЧЕСКОМ ДИЗАЙНЕ

Статья посвящена анализу особенностей функционирования и восприятия звучащих арт-объектов в системе урбанистического дизайна. Базируясь на материалах полевых исследований, проведенных в 2017-2018 гг. в Иерусалиме, автор рассматривает четыре звуковые инсталляции, размещенные в публичных пространствах города. Основное внимание в работе концентрируется на аудиальном аспекте как смысловой доминанте и факторе интерактивности. Исследуя влияние аудиального компонента на коммуникативность художественных объектов, автор приходит к выводу, что описанные звуковые инсталляции меняют характер коммуникации с пространством и внутри него, создавая территории для активного взаимодействия и креативности городских жителей.

Адрес статьи: www.gramota.net/materials/9/2018/12-1/37.html

\section{Источник}

Манускрипт

Тамбов: Грамота, 2018. № 12(98). Ч. 1. С. 168-173. ISSN 2618-9690.

Адрес журнала: www.gramota.net/editions/9.html

Содержание данного номера журнала: www.gramota.net/materials/9/2018/12-1/

\section{() Издательство "Грамота"}

Информация о возможности публикации статей в журнале размещена на Интернет сайте издательства: www.gramota.net Вопросы, связанные с публикациями научных материалов, редакция просит направлять на адрес: hist@gramota.net 
Статья посвящена анализу особенностей функционирования и восприятия звучащих арт-объектов в системе урбанистического дизайна. Базируясь на материалах полевых исследований, проведенных в 2017-2018 г2. в Иерусалиме, автор рассматривает четыре звуковые инсталлячии, размещенные в публичных пространствах города. Основное внимание в работе концентрируется на аудиальном аспекте как смысловой доминанте и факторе интерактивности. Исследуя влияние аудиального компонента на коммуникативность художественных объектов, автор приходит к выводу, что описанные звуковые инсталляии меняют характер коммуникации с пространством и внутри него, создавая территории для активного взаимодействия и креативности городских жителей.

Ключевые слова и фразы: урбанистический дизайн; публичные пространства; звучащие арт-объекты; звуковые инсталляции; креативность; городская культура.

\section{Ротенберг Натали}

Российский институт истории искусств, г. Санкт-Петербург

inmixto@gmail.com

\section{МУЗЫКА ПУБЛИЧНЫХ ПРОСТРАНСТВ: ЗВУЧАЩИЕ АРТ-ОБЪЕКТЫ В УРБАНИСТИЧЕСКОМ ДИЗАЙНЕ}

Для городского дизайна постиндустриальной эпохи одной из первостепенных целей является «преодоление отчуждения человека в городе» $[8$, с. 5]. По мысли философа Б. Гройса, огромные скопления людей в мегаполисах - «это одинокая толпа, толпа, которая общества не создает» [3, с. 5]. Современные публичные урбанистические пространства в этой связи призваны стать своего рода «лабораториями по производству событий», которые в идеале окажутся способными актуализировать социальные связи, пробудить чувство принадлежности к городскому сообществу. Американский экономист П. Ф. Колвелл охарактеризовал публичное пространство (в духе идей М. М. Бахтина) как локус, откуда нельзя изолировать (исключить) Другого [11], по сути, как арену встречи с Другим. Именно здесь проявляется социабельность - качество публичности, которое Дж. Вайнтрауб определил как коммуникацию незнакомцев [19]. Задача городского дизайна моделировать, конструировать среду, где будет возможна такого рода коммуникация.

В проектировании и оформлении публичных пространств широко используются арт-объекты: исследователи отмечают их важную социокультурную роль как «носителей информации и эмоциональных смыслов, закодированных в художественном образе» [2], и как средства «обеспечения психологического комфорта личности» [5]. Арт-объекты - «элементы нового объектного мира», творящегося «на границе между работой дизайнера и творчеством художника» [1], - меняют характер коммуникации с пространством и внутри него, создавая территории для взаимодействия и выражения разнообразия.

Необходимо подчеркнуть, что городские пространства (и публичные в том числе) могут структурироваться, определяться и распознаваться не только с помощью различных форм визуальности (материальноархитектурных объектов), но и посредством звука. Более того, звуки представляют собой неотъемлемую часть урбанистического пейзажа (справедливости ради здесь следовало бы упомянуть также запахи, температуру, тактильные и вкусовые ощущения, но эти вопросы выходят за рамки данного исследования).

В статье рассматриваются четыре арт-объекта, созданные израильскими дизайнерами в содружестве с музыкантами и экспонировавшиеся в 2017-2018 гг. на улицах Иерусалима. Целью данной работы является анализ особенностей функционирования звучащих арт-объектов в системе городского дизайна, определение их роли в конституировании общественных урбанистических пространств, а также поиск ответа на вопрос, в чем состоит существенное отличие звучащих арт-объектов от «безмолвных» произведений урбанистических визуальных художественных практик.

В силу синтетичности, гибридности анализируемых арт-объектов неизбежно возникают проблемы категоризации. Анализируемые многомерные художественные композиции, соединяющие аудиальное и визуальное, то есть базирующиеся на взаимодействии художественных кодов мусического и пластического искусств, в соответствии с их формальными, техническими и перцептивными характеристиками могут быть определены как разновидности звуковых инсталляций [13].

Несмотря на то, что данный термин вошел в искусствоведческий дискурс лишь в 1980-х гг., ранние образцы звуковых инсталляций появились еще в начале XX в. в результате творческих экспериментов музыкального авангарда и были преимущественно интерьерными объектами, то есть создавались в закрытых пространствах - от жилого помещения (Л. М. Янг) до выставочного павильона (Я. Ксенакис). В наши дни ситуация изменилась: звуковые инсталляции все чаще размещаются на открытом воздухе, на улицах, они занимают все более значимое место в городском ландшафте. Этот жанр современного искусства характеризуется самими художниками нынешнего столетия как модный, «трендовый»; арт-объекты такого рода часто пользуются спросом у муниципальных властей и вызывают интерес горожан. Актуальность исследования обуславливается потребностью в осмыслении роли звучащих арт-объектов, интегрирующих достижения технологий и новые средства художественной выразительности и в настоящее время активно расширяющих поле присутствия и сферу влияния в системе урбанистического дизайна. 
Общественные проекты, о которых далее пойдет речь, реализованы при содействии компании «Эден», занимающейся вопросами развития центра города при муниципалитете Иерусалима. Город семидесяти имен, место зарождения и столкновения трех авраамических религий, ныне постоянно живущий под прицелом камер новостных агентств всего мира, город «преемственности и сосуществования... изменчивый, знавший времена расцвета и упадка, многократно разрушенный и отстроенный заново» [6, с. 9-10], метрополия богатейшей полифонии культур и этносов, современный Иерусалим - идеальная площадка для социальных и художественных экспериментов.

Тем не менее на данный момент последовательного картографирования иерусалимского аудиального ландшафта еще не проводилось; единственный подобный опыт осуществлялся преимущественно на территории Старого Города в рамках недельного семинара по композиции, организованного Иерусалимской Академией Музыки и Танца при поддержке Еврейского Университета и Института Гете в 1999-м г. в прошлом веке! Таким образом, данная статья является шагом на пути к дальнейшему всестороннему исследованию аудиоидентичности Иерусалима, которое призвано расширить не только хронологические границы, но и спектр изучаемых явлений, что позволяет говорить о научной новизне работы. Автор фокусируется прежде всего на звуке как смысловой доминанте, его коррелятивных связях с визуальной составляющей, а также на том воздействии, которое аудиальный компонент оказывает на опыт зрительного восприятия анализируемых арт-объектов.

“The Royal Playback Orchestra” («Королевский плейбэк-оркестр») (Рис. 1)

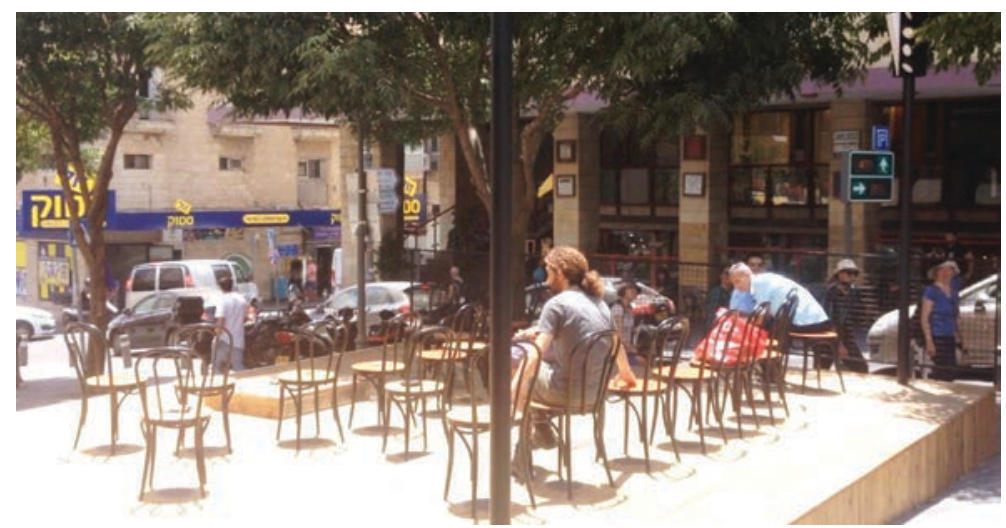

Рисунок 1. "The Royal Playback Orchestra"

экспонировался в центре Иерусалима на улище Гилель с июля по октябрь 2017 г.

Арт-объект, созданный в израильской студии “City Peloton” архитектором Иланом Берманом и художником Анат Берман и в просторечье именуемый «оркестровые», или «симфонические стулья», представляет собой открытую сцену с подиумом (возвышением для дирижера) и двадцатью фиксированными стульями, расположение которых примерно соответствует рассадке музыкантов камерного оркестра. Сиденья оснащены скрытыми динамиками, которые активируются датчиком, стоит лишь занять место «гипотетического исполнителя» [12]. При этом транслируется определенная оркестровая партия-паттерн. Когда все места заняты, звучит оркестровое tutti. Это, по сути, бесплатное «представление оркестра», открытое для самой широкой публики; более того, не ограничиваясь позицией наблюдателя, любой, кто когда-либо мечтал стать музыкантом, теперь может включиться в «игру» в качестве участника ансамбля - скрипача, тромбониста или дирижера. В названии работы сокрыта аллюзия: плейбэк-оркестр «созвучен» плейбэк-театру - перформативной художественной практике групповой импровизации, которая вторгается в реальную жизнь, стирая границу между актером, зрителем, режиссером и автором-сценаристом; плейбэк-театр, как и плейбэк-оркестр, ориентирован на производство смыслов в рамках среды. Такой опыт, по мнению авторов, формирует восприятие города как сценического пространства, где реализуются музыкальные и актерские потенции homo urbanicus, и, кроме того, может способствовать привлечению слушателей на концерты симфонической музыки академического направления.

Звуковой ряд для «Королевского оркестра» был подготовлен Йонатаном Гольдштейном, молодым израильским музыкальным продюсером, чьи работы получили известность и за пределами страны. В качестве музыкального материала автором были использованы записи иерусалимских уличных музыкантов; формообразующим принципом была избрана полиостинатность: отдельные многократно повторяющиеся («зацикленные») мелодико-ритмические паттерны (в джазе, поп- и рок-музыке чаще именуемые «рифф» (этимология неясна), в электронной музыке - “lоор” (петля)) объединяются в остинатные блоки, как в произведениях минималистов, работающих в репетитивной технике (С. Райх, Т. Райли, Ф. Гласс), или в более ранних полифонических формах западной музыки (от средневековых месс на cantus firmus до И. Стравинского и М. Равеля). При этом порядок вступления и число голосов случайны, как в алеаторических композициях, где принцип случайности (от лат. “аlea” - жребий, игральная кость) проявлен на уровне исполнения. Генетически связанная с западноевропейской и американской традицией, композиция для “Тhe Royal Playback Orchestra” вместе с тем отсылает слушателя и к восточным музыкальным практикам с присущей им медитативной повторностью. Возвращаясь к неймингу, нужно добавить, что “рlayback” в музыкальной индустрии это воспроизводящее устройство, фонограмма, а также повторное прослушивание; этот семантический 
пласт, «зашифрованный» в названии, соотносится с описанными выше формальными признаками звуковой композиции и техническим принципом работы арт-объекта.

Объект мобилен: с октября 2017 г. “The Royal Playback Orchestra” «гастролирует» в крупных городах по всему миру, задерживаясь в каждом на несколько недель [Ibidem].

Следует отметить, что, обладая художественной ценностью, «симфонические стулья» могут использоваться и в утилитарном плане - как уличная мебель: их человекосоразмерность делает их просто местом отдыха, альтернативой обычной скамейки, что кажется несомненным бонусом для городской среды.

“Kol Israel from Jerusalem” («Голос Израиля из Иерусалима») (Рис. 2)

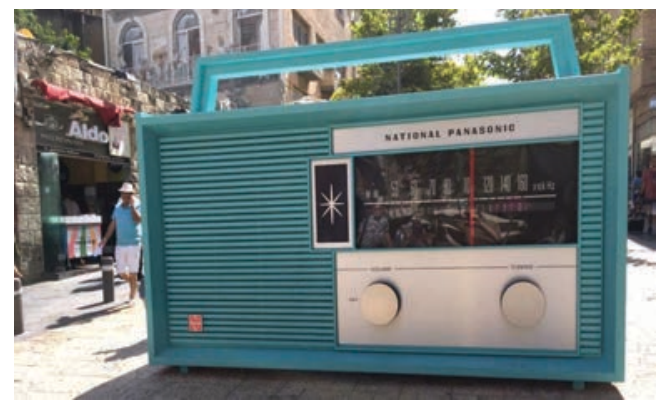

Рисунок 2. “Kol Israel from Jerusalem” экспонировался на улице Бен-Иегуда с июля по октябрь 2017 г.

Инсталляция в виде огромного радио, размещенная в центре города, задумана авторами как реминисценция: когда-то радио было «информационным центром» дома, вокруг него собрались члены семьи, чтобы услышать речи политических лидеров, узнать последние известия. Шло время; экран телевизора, а вслед за ним монитор компьютера вытеснили радио сначала на кухню, затем и вовсе прочь из жилья - в машину [Ibidem]. Возможно, однако, именно радиовещание, воплотившее, по Маклюэну, «в корне архаичную власть» [15, S. 341], способно напомнить миру разрозненных индивидов о коллективности, вернув урбанистическое атомизированное общество к общинности - пусть на время? И это не только пространственная композиция, это действительно полноценное радио, которое функционирует: прохожие могут выбрать канал вещания, поворачивая ручку переключателя, могут регулировать громкость. «Уличное радио» не транслирует «Новости», его каналы настроены исключительно на музыку. Здесь пять музыкальных станций: это радиостанции средиземноморской, классической и современной поп- и рок-музыки (с хит-парадами), а также радиостанция израильских ретро-программ 1960-1970-х гг. «Ностальгия». Проект реализован в сотрудничестве с Израильской государственной корпорацией телерадиовещания «Кан».

По замыслу создателей, объект призван не просто привлечь туристов как очередная декорация для забавного селфи: благодаря транслируемому «контенту» (музыкально-информационному наполнению) прохожие вольно или невольно оказываются вовлеченными в диалог с локальной музыкальной культурой, ее настоящим и прошлым, интуитивно ощущая ее соотнесенность с глобальным контекстом.

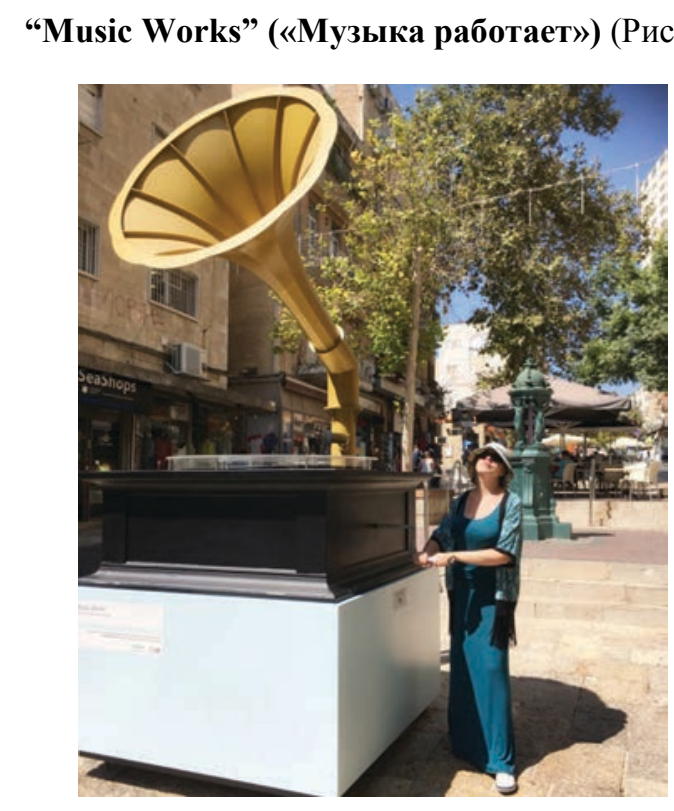

Рисунок 3. “Music Works” экспонируется на улице Бен-Иегуда с марта 2018 2.

Для активации арт-объекта, построенного в виде гигантского граммофона, прохожим предлагается совершить определенное физическое усилие: чтобы из динамика в раструбе зазвучала музыка, следует вращать 
ручку граммофона по часовой стрелке. Когда вращение прекращается, звуки стихают, заставляя задуматься: как давно мы действительно прилагали усилия, чтобы услышать музыку [12]? В этом усилии - нечто большее, чем простое нажатие кнопки, - это своеобразный вызов Человеку Кликающему [9]. В некотором роде граммофон функционирует как «тренажер»: в этом и отсылка к телесным практикам современности - увлечению здоровым образом жизни, борьбой с гиподинамией, и некая де-виртуализация, вызванная физическим действием, напоминающая, что музыка («производство» музыки в разных ипостасях, музицирование) - это не просто развлечение, но труд, достойный уважения. Знаменательно, что установка гигантского граммофона была приурочена к одному из городских фестивалей уличной музыки. Единственный момент, который оказался не учтен дизайнерами: размещенный у площади Сиона, места сосредоточения реальных, «живых» уличных музыкантов, граммофон создает звуковые помехи, превращаясь в конкурента в борьбе за звуковую нишу. Любопытно, что граммофон сам стал плоскостью для граффити (райтинга); загадочная надпись, появившаяся на корпусе в августе 2018 г., в переводе с иврита звучит как «трубы и милосердие». Происхождение граффити по сей день неизвестно, и посему остается лишь догадываться, отсылка ли это к мидрашу (разделу устной Торы), где упоминается пара труб Моисея, отлитых из одного куска серебра и олицетворявших «осуждение» и «милосердие» в их равнодействии, или закодированное обращение-протест уличных музыкантов.

Основу репертуара звуковой инсталляции составляет израильская популярная музыка 1960-1970-х гг. Звуковые дорожки воспроизводятся в случайном порядке, как при активизации функции “Random" при прослушивании компакт-диска. Например, здесь можно услышать песни из фильма-мюзикла «Касабланка» (1973 г., композитор Д. Зельтер), в котором затрагивается ряд проблем израильского общества, в том числе сложные отношения ашкеназских евреев и репатриантов из стран Востока и межэтнические браки. Таким образом, из раструба граммофона доносится музыкальный призыв к терпимости и консолидации: и мы надеемся на лучшее, ведь в финале мюзикла любовь оказывается сильнее ксенофобии.

Радио и граммофон вынесены в публичную сферу (на улицу) из приватной, личной среды - практически из домашнего обихода. Эта «инверсия» изменяет восприятие, превращая город в дом - метафору защищенности [7, с. 116-117]. Посему гипертрофированные размеры, вызывающие ассоциации с другими произведениями паблик-арта - гигантскими прищепками или громадными воланами Класа Олденбурга, оказываются вполне пропорциональны городу-дому. А еще оба они - пришельцы из другого времени, мемориаль - хранилища исторической памяти, аудиогиды в «музее» городского пространства.

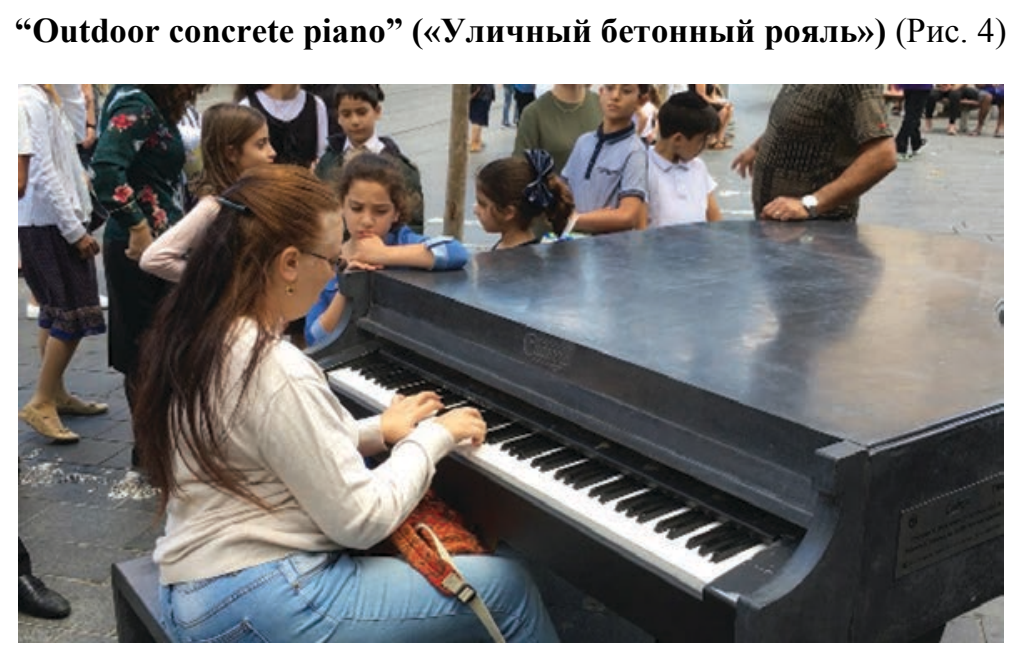

Рисунок 4. “Outdoor concrete piano” установлен на площуади Сафра в 2017 г.

Этот инновационный старт-ап представляет собой высококачественное электрическое пианино со сложными системами усиления и дистанционного управления, которое может работать практически беспрерывно - на солнечной энергии. Создатели использовали технологические разработки военной промышленности: корпус изготовлен из композитных материалов, применяемых в ракетостроении для производства уплотнителей. Любопытно, что идеи, почерпнутые в оружейном деле, не раз вдохновляли мастеров - изготовителей музыкальных инструментов. Так, на заре истории лук послужил прообразом хордофонов, а современный мексиканский художник Педро Рейес с 2007 г. «трансформирует» в музыкальные инструменты разные виды огнестрельного оружия.

Бетонное фортепиано было построено для функционирования в общественном городском пространстве, на открытом воздухе, потому должно было обладать высокой метеоустойчивостью: в данном локусе инструменту предстояло пройти испытание прямым воздействием солнечных лучей, сорокаградусной жарой и песчаными бурями летом, тропическими ливнями и редкими, но обильными снегопадами зимой. Был учтен и человеческий фактор - бетонный рояль устойчив к вандализму (хотелось бы заметить, что популярная ныне практика долговременного размещения обычных фортепиано на улицах городов в понимании автора статьи - профессионального пианиста - уже в какой-то мере акт вандализма, поскольку неизбежно приводит к порче инструментов, содержание и эксплуатация которых требует особых условий). 
Авторство и реализация проекта принадлежит компании “Cadenza”, созданной израильскими предпринимателями Даном Кауфманом и Эвелин Рубин. Говоря о нейминге старт-апа, важно помнить, что одно из значений термина «каденция» - свободный раздел музыкальный формы, не фиксированный в нотном тексте, подразумевающий импровизацию и сознательно предназначенный композитором для демонстрации творческих способностей музыканта-интерпретатора [18]. Таким образом, уличное фортепиано - воплощенная фантазия о креативности городских жителей, и компания “Cadenza” видит свою миссию в том, чтобы «разжечь магию искусства везде, где люди сталкиваются с людьми» [16].

Проект был задуман как социальный: по замыслу производителей, фортепиано должно было стать полем коммуникации, где музыка объединит представителей разных этнических и возрастных групп, религиозных конфессий и политических партий, которые едва ли встретились бы в ином контексте. Эксперимент, несомненно, удался: «пилотная версия» бетонного фортепиано благополучно прошла испытание в Иерусалиме, его первая копия в феврале 2018 г. появилась в Академическом колледже Сапир в городе Сдерот на юге страны, а в перспективе данный старт-ап может стать новой экспортной отраслью Израиля.

Успех, по мнению Д. Кауфмана, проистекает во многом также из «эффекта неожиданности», из парадоксальности ситуации: рояль, традиционно считающийся атрибутом концертных залов, «мира академической музыки», установленный на улице, неизменно вызывает любопытство, привлекает внимание, провоцируя коммуникацию. Как отмечает д-р Кауфман, фортепиано доступно для прохожих, владеющих инструментом на любом уровне, будь то профессиональный пианист, начинающий любитель либо тот, кто просто хочет извлечь звук [16; 18]. Каждый может попробовать себя в амплуа уличного музыканта: Адам Ипполито, клавишник группы Леннона “Ono Plastic”, исполняющий хиты Битлз, и мальчик-ортодокс, играющий «Танец маленьких лебедей», обретают равноправие в творчестве, равные шансы быть услышанным в большом городе. Открытость к диалогу заложена в самой карнавальной природе уличного музицирования.

Музыкальный инструмент, размещенный в городской среде, наделяется свойствами инсталляции; в свою очередь, городское пространство под воздействием музыки становится продолжением, экстенсией инструмента - своего рода дополнительной «резонансной декой». Рояль посреди пешеходной улицы - метафора выхода из обыденности, возможно, даже эскапизм: бегство от агрессии, захвата территорий - к свободной креативности, рождающей чувство безопасности, которые, как и комфорт, представляются приоритетными целями нового урбанизма. В ситуации «глобальной» усталости от конфликтов и противостояния этот иной (!) городской повседневный опыт учит нас, что Город - не всегда «каменные джунгли» или «мегамашина»; усилиями художников-дизайнеров и самих горожан может быть материализована утопическая мечта о публичном пространстве как поле для игры и творчества, где «берут начало процессы интеграции разрозненных, анонимных горожан в целостное... сообщество» [4].

Из всего рассмотренного можно сделать заключение о том, что описанные в статье объекты арт-дизайна представляют собой особые разновидности звуковых инсталляций, отличительными признаками которых являются синтетичность, интерактивность, мобильность и технологичность. Важным параметром является также тип аудиального контента: во всех рассмотренных примерах это музыка, что позволяет точнее охарактеризовать данные артефакты как «омузыкаленные» арт-объекты. Звуковой контент здесь в трех случаях из четырех непосредственно связан с локальным контекстом, то есть с местными музыкальными традициями, и, соответственно, - с региональной идентичностью. Музыка становится фактором солидаризации, играет роль «языка общения», апеллируя к социокультурным кодам, к коллективной памяти. Однако, так или иначе, музыка воздействует и на неподготовленного слушателя (либо воспитанного в иной музыкальной традиции), являясь в какой-то мере особым «медиа-форматом» - «над-языковым» способом передачи информации, ведь, как отмечает британский культуролог Д. Хезмондалш, именно музыка как культурная практика «больше прочих видов коммуникации... связана с общительностью и сообществом» [10, с. 118]. Кроме того, можно предположить, что смена музыкального контента позволит адаптировать данные артефакты в самых разных контекстах, что, как отмечалось выше, говорит об их мобильности.

Одна из существенных особенностей звучащих арт-объектов состоит в том, что они подсознательно воспринимаются анимистически, поскольку, как заметил композитор и специалист в сфере акустической экологии Р. М. Шейфер, человеку свойственно одушевлять звучащие объекты, в том числе и электроакустические медиа [17, S. 103-104]. Сходным образом мыслит и создатель абстрактной музыкальной анимации О. Фишингер, проводя аналогию между звучанием (звукоизвлечением) и высвобождением некоего «скрытого духа» объекта [14, p. 196-197]. Отсюда следует вывод, что благодаря звуку пространственнопластический объект арт-дизайна в нашем восприятии персонифицируется, то есть функционирует подобно живому организму, что создает дополнительные условия для интеракции - взаимодействия человека с художественным объектом, с окружающим пространством и, наконец, горожан друг с другом.

Восприятие подобных аудиовизуальных композиций нелинейно (то есть открыто, фрагментарно, когда начало и конец перцептивного акта могут наступить в любой момент времени) и нефронтально (когда доступен любой ракурс, точка наблюдения принципиально нестатична и избирается произвольно). Аудиальный компонент создает «четвертое измерение», добавляя к пространственным координатам визуальнопластического объекта переживание времени, процессуальность, продлевая созерцание. Звук здесь - фактор интерактивности и генератор смыслов.

Будучи размещенными в публичных урбанистических пространствах (в качестве экстерьерных объектов паблик-арта), подобные артефакты призваны стереть границу между искусством и повседневностью. Таким образом, можно сделать выводы о том, что звуковые инсталляции меняют характер общественного пространства, влияют на восприятие и поведенческие модели городских жителей, суггестивно настраивая на «очеловечивание», гуманизацию городской среды, продуцируют новые семантические пласты, экстраполируя 
на Город такие метафоры, как дом, музей, сценическая площадка и даже мегаинсталляция. Под воздействием звучащих арт-объектов публичные пространства мыслятся не как зоны игнорирования или столкновения, а как «пространство... которое отвечает человеческой потребности быть вместе» [4].

Звучащие арт-объекты обладают потенциалом «глобального присутствия», подобно стрит-арту, граффити, уличной музыке или рекламе: в силу все более широкого распространения они становятся интегративным компонентом звукового ландшафта современного города. Как следствие, могут возникнуть проблемы аудиальной экологии, которые должны учитываться художниками-дизайнерами и местными властями.

Говоря о саундскейпе Иерусалима, во многом подчиненном религиозной и природной цикличности, важно отметить, что функционирование объектов саунд-арта в публичных пространствах регулируется муниципальным «законом о тишине», ориентированным на создание благоприятной аудиальной экологической обстановки. Все рассмотренные нами арт-объекты оборудованы таймером, который включается утром (в 10:00) и выключается на ночь (в 23:00). Ритм повседневной жизни, не утративший связь с солнечной активностью и биологическими часами, - в этом разительное отличие Иерусалима, скажем, от perpetuum mobile Нью-Йорка или ночной «гиперактивности» Тель-Авива и латиноамериканских метрополий. Кроме того, иерусалимские звуковые инсталляции «замолкают» в пятницу вечером на 25 часов: таким образом проявляется уважение к религиозной общине, отмечающей священный день Субботы.

Подводя итоги, можно сделать вывод, что звучащие арт-объекты, расположенные в публичных пространствах, открывают дополнительные возможности для активного участия в аудиальном дизайне городских территорий, приглашают к диалогу, трансформируют урбанистическую среду, генерируя в ней новые смыслы, порождая новые поведенческие стратегии, реализуя творческие интенции не только художниковдизайнеров, но и самих горожан. Звук как синоним жизни, движения (в пространстве) побуждает к действию и взаимодействию, в идеале - к переходу от пассивного восприятия/потребления к креативной практике.

\title{
Список источников
}

1. Абакумов Л. И., Дергач Г. И. Арт-объекты в современном средовом дизайне [Электронный ресурс]. URL: https://cyberleninka.ru/article/n/art-obekty-v-sovremennom-sredovom-dizayne (дата обращения: 10.08.2018).

2. Агранович-Пономарева Е., Мазаник А., Агранович Д. Художественные образы объектов городского арт-дизайна [Электронный ресурс] // Архитектура и строительство. 2012. № 3 (227). URL: http://ais.by/story/15087 (дата обращения: 30.08.2018).

3. Гройс Б. Публичное пространство: от пустоты к парадоксу. M.: Strelka Press, 2012. 30 c.

4. Козьякова М. И. Публичное пространство: культура репрезентации [Электронный ресурс] // Культура культуры. 2017. № 3 (15). URL: http://cult-cult.ru/public-space-culture-of-representation/ (дата обращения: 29.08.2018).

5. Малышева А. В. Арт-объекты в формировании комфортной пространственной среды современного города [Электронный ресурс] // Молодежный научный форум. Гуманитарные науки: электронный сборник статей по материалам XL студенческой международной заочной научно-практической конференции. М.: МЦНО, 2016. № 11 (39). URL: https://nauchforum.ru/archive/MNF humanities/11(39).pdf (дата обращения: 10.08.2018).

6. Монтефиоре С. С. Иерусалим: биография / пер. с англ. И. Павловой. М.: Corpus, 2017. 720 c.

7. Николаева Е. В. Фракталы городской культуры. СПб.: Страта, 2017. 251 с.

8. Птицына Л. М. Проблематизация дизайна городской среды в современной культурологии: автореф. дисс. ... к. культурологии. Челябинск, 2012. 24 с.

9. Тарасенко В. В. Человек кликающий: фрактальные метаморфозы // Информационное общество. 1999. № 1. С. 43-46.

10. Хезмондалш Д. Музыка: почему она так важна для нас / пер. с англ. И. В. Оливы. Х.: Гуманитарный Центр, 2014.240 с.

11. Colwell P. F., Scheu T. F. Public Land Use Constraints: Lot and House Configuration // Journal of Real Estate Research. 1998. Vol. 16. № 2. P. 201-218.

12. https://www.citypeloton.com/ (дата обращения: 08.09.2018).

13. Iturbide M. R. The sound installation [Электронный ресурс] // International Computer Music Conference Proceedings. URL: https://quod.lib.umich.edu/i/icmc/bbp2372.2007.114/1 (дата обращения: 05.09.2018).

14. Kahn D. Noise, Water, Meat: A History of Sound in the Arts. Cambridge: MIT Press, 2001. 466 p.

15. McLuhan M. Die magischen Kanäle. Düsseldorf - Wien - N. Y. - M.: Econ Verlag, 1992. 407 S.

16. Rise Sh. Presenting Israeli entrepreneurs' latest innovation success story: the all-weather street ріапо [Электронный pecypc]. URL: https://www.timeout.com/israel/news/presenting-israeli-entrepreneurs-latest-innovation-success-story-the-allweather-street-piano-022118 (дата обращения: 10.08.2018).

17. Schafer M. Klang und Krach. Eine Kulturgeschichte des Hörens (1977). Frankfurt am Main: Athenäum, 1988. 317 S.

18. Steinberg J. Social piano experiment has Jerusalem passerby keyed up [Электронный pecypc]. URL: https://www.timesofisrael. com/social-piano-experiment-has-jerusalem-passersby-keyed-up/ (дата обращения: 10.08.2018).

19. Weintraub J. The theory and politics of the public/private distinction // Public and Private in Thought and Practice / ed. by J. Weintraub and K. Kumar. Chicago: University of Chicago Press, 1997. P. 1-37.

\section{MUSIC OF PUBLIC SPACES: SOUNDING ART-OBJECTS IN URBAN DESIGN}

\author{
Rotenberg Nathalie \\ Russian Institute for the History of the Arts, Saint Petersburg \\ inmixto@gmail.com
}

The article is devoted to the analysis of the peculiarities of the functioning and perception of sounding art objects in the system of urban design. Basing on the materials of the field studies conducted in 2017-2018 in Jerusalem, the author considers four sound installations located in the public spaces of the city. The main attention is focused on the audio aspect as the meaningful dominant and the factor of interactivity. Investigating the influence of the audio component on the communicative nature of artistic objects, the paper concludes that the described sound installations change the nature of communication with and within the space, creating areas for active interaction and creativity of the city dwellers.

Key words and phrases: urban design; public spaces; sounding art objects; sound installations; creativity; urban culture. 